\title{
Research of authentic leadership and abusive supervision on Team Innovation Performance
}

\author{
He Qiaoyun ${ }^{1,2, a}$, liu Yang ${ }^{1, b}$ and Wang Zhongbiao ${ }^{1, c}$ \\ 1 Guangdong Polytechnic of Science and Technology, ZhuHai, China \\ 2 South China Univercity of Technology, GuangZhou, China

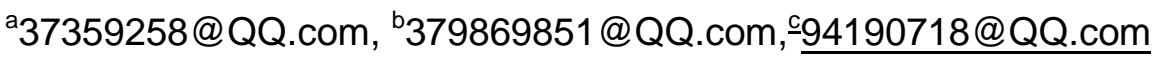

Keywords: leadership behaviors, team innovation performance, heuristic model of team effectiveness

\begin{abstract}
Modern enterprises apply the work type of team extensively. Team leadership has been confirmed to be an important key factor in all the factors influencing team effectiveness. The paper adopts purposive sampling in questionnaire. In the research, the author selects teams in 16 enterprises and institutions in five cities, respectively Beijing, Shanghai, Guangzhou, Shenzhen and Zhuhai as the research target. In order to avoid single source bias, the study classifies variables into team leaders and members and conducts questionnaire survey at $\mathrm{T} 1$ and $\mathrm{T} 2$ stage with the temporal distance of three months. Research results reveal what leading behaviors leaders should adopt to guide team members so as to improve team innovation performance, enable enterprises to make innovative achievements as well as keep competitive and sustainable.
\end{abstract}

\section{Introduction : Research Background}

The research indicates that team innovation performance is influence by many factors. However, in recent years, leadership has achieved attention as an important factor affecting team innovation. Leadership has always been a hot research topic attracting administration scholars. The research orientation on leadership can be roughly classified into 2 categories. One is to study effective leadership behavior and its positive effect on subordinates, team and organization from the positive perspective, and the research orientation has always been the mainstream. And one is to study effective leadership behavior and its positive effect on subordinates, team and organization from the negative perspective, and the research orientation was ignored in previous studies on leadership and has attracted scholars' attention gradually in recent years such as abusive supervision proposed by Tepper in 2000, tyrant behavior proposed by Ashforth in 1997, authoritarianism leadership proposed by Zheng Boxun in 1995 and bullying behavior proposed by Einarsen in 1999, etc. Some achievements have been achieved by the study on negative leadership behavior at present, which indicates that the field also has the trend of vigorous development and expansion.

\section{Concept Definition}

In 2007, Endrissat and Muller and Baum pointed that authentic leadership was the origin of positive leadership styles including transformational leadership, moral leadership and charismatic leadership[1]. The concept of authentic leadership originated in the events of leaders lacking morals such as Worldcom, Worldcom and Martha Stewart, and the increase of more and more social challenges such as 911 terrorist attacks, stock market fluctuation in USA, economic depression and 
SARS, which needs more positive leadership theories to restore people's confidence[2,3]. Many researches claim that the existing frameworks of leadership theory can't cultivate the leaders needed in the future.

In 2007, Tepper defined the concept of abusive supervision from 4 aspects [4], that is, (1) it expresses the hostility of managers on the particular subordinates, (2) it excludes infringement in some respects such as bodily injury, sexual harassment, etc. (3) it is an intentional behavior, (4) abusive supervisors don't have the intention of adverse consequences. The four dimensions can distinguish abusive supervision from other related concepts. From the concept of abusive supervision, we can summarize the following characteristics, subjectivity, constancy, hostility and non physical contact.

Team innovation means some new ideas, processes, products or procedures for the team which are introduced and applied consciously to benefit individual, team, organization and even the whole society. Team innovation performance is effective output in the process of executing innovation mission for the team, which reflects the completion of innovation objectives.

\section{Research Framework}

In traditional researches relating to team, IPO (input- process- output) model was proposed by McGrath[5-7] in 1964 and is the framework which is most commonly used. Input is a factor influencing team effectiveness, process is interactive process among team members and output means team effectiveness. In this model, team process is considered to be an important mechanism to connect team input variables and team output variables. In recent years, researches relating to team have surpassed traditional ideas only observing team process. And the concept reflecting team cognition, motivation or emotion and team status are incorporated into the researches on team input and team output so as to stretch the framework of IPO type.

In addition to the external environment, heuristic model of team effectiveness proposed by Cohen and Bailey in 1997 includes four important variables of team level [8-12]. The fist variable is task design of team (including autonomy, interdependence and so on in a team), constitution (including size, formation age in a team) and situation (including leadership and award, etc.). The second variable is team process. The third variable is mental characteristics of team. The fourth variable is team effectiveness (including performance).

According to Heuristic model of team effectiveness, positive and negative leadership behavior can be considered to be a situational factor of team, which has an influence on team process and team status and has a final effect on team effectiveness (team innovation performance).

\section{Empirical Analysis}

Questionnaire. In order to guarantee that the collected sample data is effective, we take a lot of time and energy in the research. A small amount of improved questionnaire were given out at first. After collection, the existing problems in the questionnaire are adjusted, and explanation is attached to the place which can appear problems easily, which ensure that the respondents have clear and consistent understanding on the problems. Then large-scale questionnaire is made. We make serious field interview on some concrete detailed questions. 
The respondents included senior leadership teams of more than 40 enterprises in China, and there were 164 teams participating in the survey. There were 250 pieces of questionnaire, 181 pieces were recycled, and the effective recovery was $65.6 \%$ [13-15].

Descriptive Statistics of Each Variable. The study relates to reliability coefficient of the average value, standard deviation, relevant matrix and variable measurement.

Hierarchical Regression Analysis. We adopt hierarchical regression analysis to reveal the influence of leader behaviors on enterprise organization performance. Meanwhile, we investigate the buffering effect of environmental dynamics and enterprise development phase in the influence relationship [16-17]. Because industry and enterprise development stage are classified virtual variable whose standard regression coefficients have no significance. So only non-standard regression coefficients are given in the result of hierarchical regression analysis. We can know from the fifth step of hierarchical regression analysis that environmental dynamics has evident buffering effect on the process of financial performance, growth performance and innovation performance, but environmental dynamics only has evident buffering effect on abusive type of financial performance and growth performance. We can see from the sixth step of hierarchical regression analysis that development stage of enterprise has evident buffering effect on the process of financial performance and growth performance. As there is little significance in analyzing two interactions in the situation of three evident interactions, the concrete condition of buffering effect for environmental dynamics and enterprise development must be indicated firstly by the analysis of three interactions.

We can know from the seventh step of hierarchical regression analysis that environmental dynamics has different buffering effect on the process of financial performance, growth performance and innovation performance. From further analysis, we can find that the influence of authentic type of leadership for leaders on financial performance is adjusted evidently by environmental dynamics. The positive influence of authentic type of leadership for leaders on financial performance in the condition of high environmental dynamics was stronger evidently than that in the condition of low environmental dynamics. In mature stage of enterprise, although environmental dynamics has no buffering effect on the influence of authentic type of leadership for leaders on financial performance, the mode of authentic type of leadership for leaders influencing financial performance changes, that is, authentic type of leadership for leaders in the condition of low environmental dynamics can achieve better financial performance than that in the condition of high environmental dynamics.

From the significance of slope and difference, we can see that in the survival and development stage, the slope of authentic type of leadership is greater evidently than 0 no matter in the condition of low environmental dynamics or in the condition of high environmental dynamics. But in the mature stage, there is no evident difference between the slope of authentic type of leadership and 0 no matter in the condition of low environmental dynamics or in the condition of high environmental dynamics. In the situation of the same environmental dynamics, the slope of authentic type of leadership has no evident difference in survival and development stage and is greater than that in the mature stage, which indicates that authentic type of leadership has positive influence on the financial performance in survival and development stage of enterprise. But the influence is not evident in the mature stage, and the positive influence in survival stage is similar to that in development stage and are stronger evidently the effect in the mature stage. From further analysis, we can find that the influence of authentic type of leadership for leaders on financial performance is adjusted evidently by environmental dynamics. 
The negative influence of authentic type of leadership for leaders on financial performance in the condition of high environmental dynamics is greater evidently than that in the condition of low environmental dynamics. But environmental dynamics has no evident buffering effect on the mature stage. From the significance of the slope and difference, we can find that in the survival and development stage, there is no evident difference between the slope of authentic type of leadership and 0 in the condition of low environmental dynamics, but the slope of authentic type of leadership is greater evidently than 0 in mature stage. The slope of authentic type of leadership in the condition of high environmental dynamics is less significantly than 0, and the slope of authentic type of leadership in mature stage has no evident difference with 0. And in the condition of high environmental dynamics, the difference in the slope of authentic type of leadership between the survival stage and development stage of enterprise is not evident, and the slope is less evidently than that in the mature stage, which indicates that in the condition of high environmental dynamics, the influence of abusive leadership on financial performance is negative, but in the mature stage, abusive leadership has positive influence in the condition of low environmental dynamics. We can see that in different development stage of enterprise, the mode of environmental dynamics on authentic type of leadership influencing growth performance is similar to the mode of environmental dynamics on authentic type of leadership influencing financial performance.

From further analysis, we can find that in the survival and development stage of enterprise, the influence of authentic type of leadership for leaders on financial performance is evidently adjusted by environmental dynamics. The positive influence of environmental dynamics on financial performance in the condition of high environmental dynamics is greater significantly than that in the condition of low environmental dynamics, but there is no buffering effect of environmental dynamics in mature stage. We can see from the significance of the slope and difference in inspection interaction diagram that the slope of authentic type of leadership in the survival and development stage in the condition of high environmental dynamics is greater evidently than 0 , but the slope of authentic type of leadership in mature stage is not greater than 0 , and there is no evident difference between two stages in the slope of authentic type of leadership. In the condition of low environmental dynamics, only the slope of authentic type of leadership in survival stage is greater evidently than 0 and that in development and mature stage, which indicates that authentic type of leadership is very important in survival stage.

As the condition that three interactive items are not evident needs to analyze two interactions, and the condition that three interactive items and two interactions are not significant needs to analyze main effect [18]. Therefore, when the seventh step in hierarchical regression analysis has no evident moderating effect, it is necessary to analyze the corresponding parts of the fifth and sixth step in hierarchical regression analysis. From the fifth step in hierarchical regression analysis, we can see that environmental dynamics has evident adjustment effect on abusive leadership influencing the process of growth performance and on authentic type of leadership influencing innovation performance. From further analysis, we can see that abusive leadership has evident negative effect on growth performance in the condition of high environmental dynamics, and the influence of abusive leadership on growth performance is not evident in the condition of low environmental dynamics. The positive influence of authentic type of leadership on innovation performance in the condition of high environmental dynamics is significant, but that in the condition of low environmental dynamics is not evident. We can see from the sixth step in hierarchical regression analysis that the development stage of enterprise has evident adjustment effect on abusive leadership influencing growth performance and innovation performance. From further analysis, we can find that the negative influence of abusive leadership on growth performance in development stage is greater than that in survival stage, but there is no evident negative influence on growth performance in mature stage, and abusive leadership has evident 
positive influence on innovation performance, but there is evident negative influence of abusive leadership on innovation performance in survival and development stage.

\section{Conclusion and future research Direction}

The study exist some limitations inevitably: teams of the research came from different groups and different types of organizations; the work is different and we can not measure team innovation performances by objective indicator of innovation performances so the evaluations of team innovation performances were subjective assessments which made by team leaders; for the statistic analysis of multiple regression, sample sizes for research were still less, for the numbers of teams which had their own characteristics, they didn't meet the requirements of large samples investigation. The scales which used by the research were all had good reliabilities and validities in the past research and in research of this time but after the measure of multidimensional concept of sincere leading and improper supervision behaviors, the significance of the researches may change and it may be one of the reason why the main effects were not distinct in the research results. In feature research, we can take objective indicators of innovation performances to measure sincere leading and improper supervision behaviors more fully and verify the conclusion of the research.

\section{Acknowledgements}

This paper is supported by Foundation for Training program of Distinguished Young Teachers in Higher Education of Guangdong Province, China(Grand No.Yq2014189).

\section{References}

[1] Katzenbach, J. R. \& Smith, D. K., 1993. The wisdom of teams: Creating the high-performance organization. New York: Happer Collins.

[2] Cropanzano, R., \& Mitchell, M. Social exchange theory: An interdisciplinary review. Journal of Management, 31, 874-900 (2005).

[3] Bass, B. M., \& leadership questionnaire. CA: Consulting Psychologists Press

[4] Tepper B J. Consequences of abusive supervision. Academy of Management Journal, 43(2): 178-190 (2014).

[5] Hollander, EP, Offermann, L. Power and leadership in organizations: Relationships in transition. American Psychologist 45: pp. 179-189 (1990).

[6] Podsakoff, P. M., Todor, W. D., Grover, R. A, \& Huber, V. L. Situational moderators of leader reward and punishment behavior: Fact or fiction? Organizational Behavior and Human Performance, 34: 21-63 (1984).

[7] Bass B M. Leadership and Performance beyond Expectation. New York: Free Press, (1985)

[8] Podsakoff, P. M., MacKenzie, S. B., \& Bommer, W. H., Transformational leader behaviors and substitutes for leadership as determinants of employee satisfaction, commitment, trust, and organizational citizenship behaviors. Journal of Management, 22: 259-298 (1996).

[9] Harris K J, Kacmar M, Zivnuska S. An investigation of abusive supervision as a predictor of performance and the meaning of work as a moderator of the relationship. Leadership Quarterly, 18: 252-263 (2012).

[10] Zellars, K L, Tepper, B J, Duffy, M K. Abusive supervision and subordinates organizational citizenship behavior . Journal of Applied Psychology, 2002, 87: 1068-1076.

[11] Damanpour, Fariborz, 1991, Organizational innovation: a meta-analysis of effects of determinants and moderators, Academy of management journal, Vol 34, No. 3, 555-590.

[12] Hurley.R. \& Hult.G., Innovation,market orientation, and organizational learning:An integration and empirical examination. Journal of Marketing, 1998, 62(3), 42-45.

[13] Dumaine. The troublewith teams. Fortune, 1994(5): 86-89. 
[14] Kahai S S, Sosilk J J, Avolio B J. Effects of leadership style and problem structure on work group process and outcomes in an electronic meeting system environment. Personnel Psychology, 1997, 50: 121-146.

[15] Schminke.M. \& Wells.D..Group process and performance and their effects on individuals'ethical frameworks. Journal of Business Ethics, 1999(18): 367-381.

[16] BARRICK M R, STEWART G L, NEUBERT M.J, et al. Relating Member Ability and Personality to Work-team Processes and Team Effectiveness. Journal of Applied Psychology, 1998, 83(3): 377-391.

[17] Early, P. C. \& Mosakowski, E., 2013. Creating hybrid team cultures: An empirical test of transnational team functioning. Academy of Management Journal, 43(1): 26-49.

[18] Lovelace, K., Shapiro, D. L. \& Weingart, L. R. Maximizing cross-functional new product teams'innovativeness and constraint adherence: A conflict communications perspective. Academy of Management Journal, 2011, 44: 779 -793. 